JP3I (Jurnal Pengukuran Psikologi dan Pendidikan Indonesia), 9(I), 2020, 19-29

DOl: http://dx.doi.org/l0.15408/ip3i.v9il.13329

http://journal.uinjkt.ac.id/index.php/jp3i

\title{
Maslach Burnout Inventory-Human Services Survey (MBI-HSS) Versi Bahasa Indonesia: Studi Validasi Konstruk pada Anggota Polisi
}

\author{
Heri Yulianto \\ UIN Syarif Hidayatullah Jakarta, Indonesia \\ heripsi@polri.go.id
}

\begin{abstract}
One of the professions that has a high risk, stress and burnout rate is the police. To find out the extent of police officers against the impact of burnout, we need a valid and reliable measurement tool. This research seeks to test the construct validity of the Maslach Burnout Inventory-Human-Services Survey (MBI-HSS). The data used are data obtained from 504 police officers serving in the Metro Jaya Regional Police (Polda Metro Jaya); age between 21 and 56 years old (M $=33.04, S D=8.533)$; male sex $(99.8 \%)$ and female $(0.2 \%)$; and length of work from 3-38 years $(M=15.04, S D=$ 8.533). The analytical method used is Confirmatory Factor Analysis (CFA) using Mplus 7.II. The test results prove that the data fit with the 3-correlated factor model that shows the correlation of emotional exhaustion and depersonalization factors $=0.966$, emotional exhaustion and personal accomplishment $=-0.590$ and personal accomplishment and depersonalization $=-0.701$, with $R M S E A=0.048, C F I=0.943$ and $T L I=0.934$, indicating good fit.
\end{abstract}

Keywords: construct validity; burnout; Maslach Burnout Inventory-Human-Services Survey (MBI-HSS); confirmatory factor analysis; police

\begin{abstract}
Abstrak
Salah satu profesi yang memiliki resiko, stress dan tingkat burnout yang tinggi adalah polisi. Untuk mengetahui sejauh mana anggota polisi terhadap dampak burnout, dibutuhkan alat ukur yang valid dan reliabel. Oleh karena itu penelitian ini bertujuan untuk menguji validitas konstruk dari skala Maslach Burnout Inventory-Human-Services Survey (MBIHSS). Data yang digunakan adalah data yang diperoleh dari 504 anggota polisi yang bertugas di Polda Metro Jaya; rentang usia 2I hingga 56 tahun $(\mathrm{M}=33,04$; $\mathrm{SD}=8,533)$; jenis kelamin laki-laki $(99,8 \%)$ dan wanita $(0,2 \%)$; masa dinas mulai 3 hingga 38 tahun $(\mathrm{M}=\mathrm{I5}, 04 ; \mathrm{SD}=8,533)$. Metode analisis yang digunakan adalah Confirmatory Factor Analysis (CFA) dengan menggunakan software Mplus version 7.II. Hasil pengujian membuktikan bahwa data fit dengan model 3-correlated factor yang menunjukkan korelasi faktor emotional exhaustion dan depersonalisation $=$ 0,966, emotional exhaustion dan personal accomplishment $=-0,590$ dan personal accomplishment dan depersonalisation $=-0,701$, dengan indeks kesesuaian RSMEA $=0,048 ;$ CFI $=0,943$; dan TLI $=0,934$.
\end{abstract}

Kata Kunci: validitas konstruk; burnout, Maslach Burnout Inventory-Human-Services Survey (MBI-HSS); analisis faktor konfirmatorik; polisi 


\section{Pendahuluan}

Burnout didefinisikan sebagai respons berkepanjangan terhadap stresor emosional dan interpersonal kronis pada pekerjaan, dan ditentukan oleh tiga dimensi yaitu kelelahan, sinisme, dan ketidakefisienan (Maslach et al., 200I). Stress kerja yang tinggi dapat merusak fisik, psikologis dan sosial, dan burnout terjadi ketika ketiga aspek tersebut memuncak. Salah satu contoh dampak karyawan yang mengalami burnout adalah dengan menghindari pekerjaan, tidak mau berurusan dengan tugas sehari-hari atau menjadi benar-benar terlibat dalam pekerjaan dan mengabaikan aspek kehidupan lainnya. Gejala-gejala yang terlihat tersebut termasuk perasaan sangat kelelahan, kehilangan kepercayaan diri, perasaan tidak berdaya, kesedihan, ketidakpuasan, frustasi, mudah marah, kekakuan, kecemasan, rasa bersalah, penolakan untuk menerima keadaan kelelahan, menyangkal penurunan efektivitas, ketidakmampuan untuk menilai secara objektif kinerja, somatisasi, seperti insomnia, sakit kepala, sakit punggung, masalah lambung, dan lainnya (Purda et al., 2012).

Penggunaan tes psikologi dalam mendiagnosis permasalahan burnout pada karyawan pada berbagai bidang pekerjaan sangat diperlukan untuk mempertahankan kehidupan emosi, performa kerja, dan kesehatan mentalnya. Salah satunya Maslach Burnout Inventory-Human Services Survey (MBI-HSS) skala burnout yang dikembangkan oleh Maslach pada tahun I98I yang telah dianggap valid dan reliabel. Skala MBI ini terdiri dari tiga dimensi yaitu emotional exhaustion, depersonalization, dan personal accomplishment (Horn et al., 1998). Uji reliabilitas pada Maslach Burnout Inventory yaitu konsistensi internal oleh koefisien alpha Cronbach, yang menghasilkan koefisien reliabilitas 0,83 (frekuensi) dan 0,84 (intensitas). Koefisien reliabilitas untuk subskala adalah 0,89 (frekuensi) dan 0,86 (intensitas) untuk emotional exhaustion, 0,74 (frekuensi) dan 0,74 (intensitas) untuk Personal Accomplishment, 0,77 (frekuensi) dan 0,72 (intensitas) untuk depersonalisation, dan 0,59 (frekuensi) dan 0,57 (intensitas) (Maslach \& Jackson, I98I).

Pada uji validitas skala MBI menunjukkan validitas konvergen yang mampu memberikan bukti substansial untuk validitas skala MBI dengan 3 (tiga) cara, yaitu pertama, skor MBI pada individu berkorelasi dengan peringkat perilaku yang dibuat secara independen oleh seseorang yang mengenalnya dengan baik (pasangan atau rekan kerja). Kedua, skor MBI berkorelasi dengan adanya karakteristik pekerjaan tertentu yang diharapkan berkontribusi untuk mengalami burnout. Ketiga, skor MBI berkorelasi dengan ukuran berbagai hasil yang telah dihipotesiskan terkait dengan burnout (Maslach \& Jackson, I98I).

Burnout adalah sindrom kelelahan secara emosional dan sinisme yang sering terjadi di antara individu yang melakukan "pekerjaan melayani orang" (Maslach \& Jackson, I98I). Profesi dengan tingkat burnout yang tinggi adalah pekerja kesehatan, pekerja sosial, guru, pengacara, perwakilan layanan pelanggan, dan petugas kepolisian (Chirico, 2016). Beberapa tahun terakhir, riset tentang burnout banyak diteliti dalam kaitannya dengan berbagai variabel tentang pekerjaan, salah satunya pekerjaan polisi. The American Institute of Stress menyatakan bahwa, profesi polisi telah masuk dalam sepuluh besar pekerjaan paling menegangkan di AS dan dikategorikan sebagai salah satu pekerjaan paling menegangkan di dunia (Purda et al., 20I2). Nikam dan Shaikh (20I4) menyatakan pekerjaan polisi sangat menegangkan karena mereka selalu harus menghadapi tantangan dalam hidup mereka dengan mengambil risiko dalam pekerjaan sehari-hari mereka, dimana polisi termasuk enam profesi dengan tingkat stress yang tinggi dan memiliki dampak pada kesehatan dan kepuasan kerja yang rendah. Beratnya tantangan dan beban tugas polisi dapat menimbulkan dampak negatif baik fisik maupun psikologis bagi polisi (Queirós, Kaiseler, \& Leitão, 2013).

Untuk dapat memenuhi tanggung jawab agar anggota polisi dapat bekerja secara professional, tentu selain pemenuhan kebutuhan fisik juga harus diperhatikan kebutuhan psikologisnya. Salah satunya adalah menghindari atau meminimalisir dampak burnout pada anggota polisi, agar setiap anggota polisi tampil dengan kondisi prima, baik fisik maupun psikologisnya. Untuk mengetahui sejauh mana anggota polisi di Indonesia terhadap dampak burnout, tentu dibutuhkan alat ukur yang valid dan reliabel. Namun demikian kurang tepat jika menggunakan alat ukur skala burnout yang dikembangkan pada latar belakang Amerika digunakan untuk mengukur burnout pada anggota polisi di Indonesia. 
Querios, Kaiseler, dan Da Silva (2013) dalam penelitian terhadap 274 anggota kepolisian Portugis dengan menggunakan 22 item skala Maslach Burnout Inventory- Human Services Survey (MBI-HSS) dan didapatkan reliability alpha cronbach pada masing-masing dimensi sebesar 0,85 pada dimensi emotional exhaustion, 0,74 pada dimensi depersonalization dan 0.79 pada dimensi personal accomplishement. Penelitian lain di Norwegia kepada I.590 perawat dan guru di dapatkan indeks fit di atas 0,90 dengan RMSEA 0,06 dengan menghapus 2 item pada skala MBI (Richardsen \& Martinussen, 2004).

Di Indonesia, penelitian psikologi tentang burnout terhadap anggota polisi masih sangat sedikit. Aditama (2003) melakukan penelitian kepada anggota polisi di Jakarta menggunakan skala burnout dan diperoleh koefisien reliabilitas sebesar 0,84 pada dimensi emotional exhaustion, 0,80 pada dimensi depersonalization, dan 0,92 pada personal accomplishement. Kemudian Muarif (2015) melakukan penelitian dengan skala MBI kepada anggota polisi di Polda Daerah Istimewa Yogyakarta dan menghasilkan nilai koefisien reliabilitas sebesar alpha 0,93 .

Penelitian lain tentang burnout pada anggota polisi yaitu Putra dan Prihatsanti (2017) melakukan penelitian terhadap 65 anggota polisi Detasemen Gegana Satuan Brigade Mobil Polda Jawa Tengah dengan menggunakan 17 item skala MBI dengan nilai koefisien reliabilitas sebesar alpha 0, 88. Hatta dan Noor (20I4) melakukan penelitian dengan adaptasi skala MBI-HSS dan diujicobakan kepada 50 anggota polisi Polrestabes Bandung.

Dari beberapa penelitian burnout pada anggota polisi di Indonesia dengan penggunaan skala MBI-HSS, meskipun alat ukur disusun berdasarkan kondisi di Indonesia tetapi menurut peneliti, alat ukur burnout yang digunakan masih memiliki kelemahan untuk dapat diterapkan kepada anggota kepolisian secara keseluruhan. Salah satu kelemahannya melalui sisi psikometris dimana pengembangan alat ukur burnout dengan teori klasik. Menurut Retnawati (2017) ada beberapa asumsi dalam teori tes klasik, yang pertama skor kesalahan pengukuran tidak berinteraksi dengan skor sebenarnya. Kedua, skor kesalahan tidak berkorelasi dengan skor sebenarnya dan skor-skor kesalahan pada tes-tes yang lain untuk peserta tes yang sama. Asumsi ketiga, rata-rata dari skor kesalahan ini sama dengan nol.

Kelemahan lain pada teori klasik adalah pertama, CTT tergantung pada orang; yaitu, hasilnya tidak dapat menyamaratakan kesulitan item dan daya pembeda lintas kelompok. Kedua, CTT bergantung pada item; yaitu kemampuan orang adalah fungsi dari kesulitan sampel item yang diberikan. Dengan demikian, tingkat kesulitan item bervariasi tergantung pada sampel peserta tes yang mengikuti tes tertentu. Ketiga, CTT bekerja dengan asumsi bahwa varians kesalahan pengukuran adalah skor yang sama dari semua orang yang diberikan instrumen (Manapsal, 2017).

Untuk mengatasi kelemahan dari penelitian dan pengembangan alat ukur burnout sebelumnya, dalam penelitian ini menggunakan pendekatan yang lebih modern dan akurat dengan menggunakan Confirmatory Factor Analysis (CFA). Oleh karena itu, peneliti melakukan penelitian dan pengembangan alat ukur burnout dengan metode adaptasi skala Maslach Burnout Inventory-Human Services Survey (MBI-HSS) yang dikembangkan oleh Maslach dan Jackson pada tahun I98I dan diterapkan kepada anggota polisi.

Dalam penelitian ini, peneliti berupaya merancang alat ukur burnout untuk kepentingan sebagai screening kondisi psikologis anggota polisi agar dapat selalu bekerja secara profesional. Skala Maslach Burnout Inventory-Human Services Survey (MBI-HSS), skala ini dibuat oleh Maslach dan Jackson pada tahun I98I yang terdiri dari 22 item yang terbagi dalam tiga aspek yaitu emotional exhaution, depersonalisation dan reduce personal accomplishment. Skala dalam penelitian ini menggunakan tujuh alternatif jawaban yaitu $(0=$ tidak pernah, I = beberapa kali setahun, 2 = sebulan sekali atau kurang, 3 = beberapa kali sebulan, $4=$ seminggu sekali, 5 = beberapa kali seminggu, $6=$ setiap hari). Responden diminta memberikan respons sesuai dengan apa yang mereka rasakan terhadap setiap item pernyataan dalam setiap kontinum dalam skala (Maslach \& Jackson, 198I). 
Pengujian validitas konstruk skala MBI-HSS pada penelitian ini dikembangkan dengan menggunakan metode Confirmatory Factor Analysis untuk membuktikan bahwa teori burnout yang dikemukakan Maslach (I98I) memenuhi asumsi unidimensionalitas. Unidimensionalitas sangat penting diteliti untuk membuktikan bahwa alat ukur yang dirancang dalam penelitian ini hanya mengukur burnout.

Selain itu, dilakukan juga pengujian untuk membuktikan apakah alat ukur burnout yang dirancang dalam penelitian ini terdiri dari item-item yang fit karena hasil ukur yang valid ditentukan oleh item-item yang fit. Pengujian ini merupakan kelebihan penggunaan pendekatan modern yang tidak pernah diuji pada pendekatan klasik.

\section{Metode}

\section{Prosedur}

Pengujian validitas konstruk Maslach Burnout Inventory (MBI) ini menggunakan pendekatan Confirmatory Factor Analysis (CFA). CFA merupakan salah satu metode yang digunakan untuk menguji struktur faktor atau construct validity suatu instrumen pengukuran atau skala psikologi. Maslach Burnout Inventory yang digunakan dalam penelitian ini akan diuji struktur faktor atau validitas konstruknya dengan pendekatan Confirmatory Factor Analysis (CFA) menggunakan software Mplus version 7.II (Muthen \& Muthen, 1998). Menurut Umar (20II) Kriteria item yang baik pada CFA adalah: (I) Melihat signifikan tidaknya item tersebut mengukur faktornya dengan melihat nilai t bagi koefisien muatan faktor item. Perbandingannya adalah jika $\mathrm{t}>$ I,96 maka item tersebut signifikan dan sebaliknya. Apabila item tersebut signifikan maka item tidak akan dieliminasi, dan sebaliknya. (2) Melihat koefisien muatan faktor dari item. Jika item tersebut sudah diskoring dengan favorable, maka nilai koefisien muatan faktor pada item harus bermuatan positif, atau sebaliknya. Apabila item tersebut favorable, namun koefisien muatan faktor item bernilai negatif maka item tersebut akan dieliminasi dan sebaliknya. (3) Terakhir, apabila kesalahan pengukuran item terlalu banyak berkorelasi, maka item tersebut akan dieliminasi. Sebab, item yang demikian selain mengukur apa yang hendak diukur, ia juga mengukur hal lain (multidimensional).

Data dalam penelitian ini dikumpulkan dengan menggunakan kuesioner yang diberikan kepada anggota kepolisian yang berdinas di Kepolisian Daerah Metro Jakarta Raya dan jajaran. Pengambilan sampel dalam penelitian ini menggunakan teknik nonprobability sampling, dimana kuesioner penelitian diberikan kepada anggota kepolisian yang sedang mendapatkan pelayanan psikologi baik berupa pemeriksaan psikologi izin pinjam pakai senjata api dan konseling psikologi pranikah. Pelaksanaan pengambilan data dilaksanakan pada bulan September dan Oktober tahun 2019. Pada awalnya jumlah kuesioner yang diperoleh sebanyak 520 sampel, namun dalam tahap input data terdapat 16 kuesioner yang tidak selesai dikerjakan sehingga dalam penelitian ini menggunakan 504 sampel.

\section{Responden}

Responden dalam penelitian ini berdinas di Polda Metro Jaya (37,7\%), Satuan Brimob Polda Metro Jaya $(8,5 \%)$ dan Polres jajaran Polda Metro Jaya (53,8\%), berusia mulai dari 2 I hingga 56 tahun $\mathrm{M}=33,04$, SD $=8,533$ ), berjenis kelamin laki-laki sebanyak 99,8\% dan wanita sebanyak 0,2\%. Golongan kepangkatan responden penelitian terdiri dari golongan Tamtama (2,2\%), Bintara (88,5\%), Perwira Pertama (7,5\%) dan Perwira Menengah ( $I, 8 \%)$ dengan masa dinas mulai dari 3 hingga 38 tahun $(M=I 5,04, S D=8,533)$.

\section{Alat Ukur}

Kuesioner dalam penelitian ini menggunakan skala Maslach Burnout Inventory (MBI-HSS) yang dibuat oleh Maslach dan Jackson pada tahun I98I yang telah diadaptasi ke dalam bahasa Indonesia serta dalam budaya kerja kepolisian dengan melibatkan 4 (empat) ahli bahasa Inggris dan 8 (delapan) psikolog kepolisian 
dengan mengacu pada jurnal Guidelines for the Process of Cross-Cultural Adaptation of Self-Report Measures (Beaton et al., 2000). Skala dalam penelitian ini terdiri dari 22 item dengan 7 (tujuh) skala likert (0 $=$ tidak pernah, $\mathrm{I}=$ beberapa kali setahun, 2 = sebulan sekali atau kurang, 3 = beberapa kali sebulan, $4=$ seminggu sekali, 5 = beberapa kali seminggu, $6=$ setiap hari).

Tabel I. Blue Print Maslach Burnrout Inventory (MBI)

\begin{tabular}{llll}
\hline \multirow{2}{*}{ Faktor } & \multicolumn{2}{l}{ Sebaran Item } & Jumlah \\
\cline { 2 - 3 } & Favourable & Unfavourabel & \\
\hline Emotional Exhausted & I, 2, 3, 6, 8, I3, I4, I6, 20 & & 9 \\
Depersonalisation & 5, I0, II, I5, 22 & 4,7, 9, I2, I7, I8, I9, 2I & 8 \\
Petsonal Accomplishment & & & 22 \\
\hline Total & & \\
\hline
\end{tabular}

\section{Analisis Data}

Confirmatory Factor Analysis (CFA) merupakan salah satu dari pendekatan utama di dalam analisis faktor, CFA dapat digunakan untuk menguji dimensionalitas suatu konstruk. Pengujian ini digunakan untuk melakukan pengukuran model (model measurement) sehingga dapat menggambarkan aspek-aspek dan indikator-indikator dalam merefleksikan variabel laten. Confirmatory Factor Analysis (CFA) juga digunakan untuk menguji validitas konstrak dan reliabilitas konstrak dari indikator-indikator (item-item) pembentuk konstruk laten.

Untuk menilai kecocokan model pengukuran benar-benar fit dengan data, perlu diperhatikan nilai indeks fit. Indek fit yang dihasilkan dari analisis menggunakan metode CFA ada berbagai macam. Suatu indeks yang menunjukkan model tersebut fit tidak memberikan jaminan bahwa model benar-benar fit, begitu pula sebaliknya. Maka dalam laporan uji validitas ini tidak hanya bergantung pada satu indek fit untuk menguji model tersebut. Sehingga dalam penelitian ini digunakan empat indeks model fit:

$$
\text { 1. Chi-square }\left(\chi^{2}\right)
$$

Uji statistik ini adalah uji statistik konvensional untuk menguji kecocokan keseluruhan model dalam SEM. Sebelum uji statistik ini dikembangkan oleh Joreskog (1969), analisis faktor hanya didasarkan pada keputusan subjektif. Uji statistik $\chi^{2}$ menjadi yang pertama dalam menunjukkan bahwa evaluasi terhadap model analisis faktor memiliki kriteria yang objektif. $\chi^{2}$ yang dicari adalah yang nilainya tidak signifikan yang artinya kesalahan pada model tidak signifikan (Wang \& Wang, 20I2).

\section{RMSEA (Root Mean Square Error of Approximation)}

RMSEA diperkenalkan oleh Steiger dan Lind tahun I980. RMSEA mengukur penyimpangan nilai parameter pada suatu model dengan matriks kovarians populasinya. Nilai RMSEA $<0,05$ mengindikasikan model fit dan nilai RMSEA yang berkisar antara 0,08 menyatakan bahwa model memiliki perkiraan kesalahan yang reasonable. Sementara nilai RMSEA yang berkisar antara 0,08 sampai dengan 0,10 menunjukkan model memiliki fit yang cukup. Sedangkan nilai RMSEA > 0,I0 menunjukkan model fit yang sangat buruk. Kesimpulannya, model dikatakan fit dengan data ketika nilai RMSEA < 0,05 (Wang \& Wang, 2012).

\section{Comparative Fit Index (CFI).}

CFI merupakan indeks kesesuaian kecocokan model yang nilainya berkisar antara 0 sampai I. Nilai CFI yang mendekati I mengindikasikan model memiliki tingkat kesesuaian yang baik. Indeks ini sangat dianjurkan untuk dipakai karena indeks ini relatif tidak sensitif terhadap besarnya sampel dan tidak terpengaruh oleh kompleksitas model. Nilai penerimaan yang direkomendasikan adalah CFI > 0,90 (Hu \& Bentler, I999)

4. $\quad$ Tucker Lewis Index (TLI) 
TLI merupakan indeks kesesuaian incremental yang membandingkan model yang diuji dengan baseline model. TLI digunakan untuk mengatasi permasalahan yang timbul akibat kompleksitas model. Nilai penerimaan yang direkomendasikan adalah nilai TLI $>0,90$. TLI merupakan indeks yang kurang dipengaruhi oleh ukuran sampel (Hu \& Bentler, I999).

Indeks model fit yang telah dipaparkan sebelumnya digunakan untuk menguji hipotesis bahwa $S=\sum$ atau dapat dituliskan $H_{0}=S-\Sigma=0$. Uji hipotesis ini misalnya dilakukan dengan menggunakan uji $\chi^{2}$, dimana jika $\chi^{2}$ tidak signifikan $(p>0,05)$, atau RMSEA, CFI dan TLI berada pada cutoff, maka dapat disimpulkan bahwa hipotesis nihil ( $\left.H_{0}\right)$ tidak ditolak, artinya teori yang mengatakan bahwa semua item mengukur burnout terbukti sesuai (fit) terhadap data

\section{Hasil dan Pembahasan}

Dalam penelitian ini, peneliti menggunakan pendekatan Confirmatory Factor Analysis (CFA) dengan membuat model pengukuran untuk menggambarkan sebaik apakah indikator-indikator dalam Maslach Burnout Inventory-Human Services Survey (MBI-HSS) ini dapat digunakan sebagai instrument pengukuran variable laten. Dalam pengujian ini, dilakukan dengan membuat model first order, second order, 3-correlated factor. Hasil pengujian model dapat dilihat pada Tabel 2.

Tabel 2. Hasil Uji Model CFA

\begin{tabular}{llll}
\hline Indeks fit & First order & Second order & 3-correlated factor \\
\hline Chi-squate & I290,I20; $\mathrm{df}=2 \mathrm{IO} ;$ & 742,$230 ; \mathrm{df}=207 ;$ & 596,$520 ; \mathrm{df}=206 ;$ \\
& p value $<0.0 \mathrm{I}$ & p value $<0.0 \mathrm{I}$ & p value $<0.0 \mathrm{I}$ \\
RSMEA & O,IOI & 0,072 & $0,06 \mathrm{I}$ \\
CFI & 0,730 & 0,866 & 0,902 \\
TLI & 0,703 & $0,85 \mathrm{I}$ & $0,89 \mathrm{I}$ \\
\hline
\end{tabular}

Dari hasil uji validitas CFA dengan menggunakan tiga model, dapat dilihat pada nilai masing-masing indeks fit dimana dari ke tiga model tersebut tidak fit karena nilai $p$-value $<0,0$ I dan nilai RSMEA $>0,05$. Namun dari Tabel 2 dapat dilihat model 3-correlated factor memiliki indeks yang lebih baik daripada dua model yang lain yaitu indeks RMSEA paling rendah (0,06I), CFI (0,902) dan TLI (0,89I).

Langkah berikutnya melakukan modifikasi terhadap model 3-correlated factor, dimana kesalahan pengukuran pada beberapa item dibebaskan berkorelasi satu sama lainnya sehingga didapatkan hasil sebagai berikut.

Tabel 3. Hasil Modifikasi Uji Model Goodness of Fit Model 3-Correlated Factor

\begin{tabular}{lll}
\hline Indeks fit & 3-correlated factor & Keterangan \\
\hline Chi-square & 429,$588 ; \mathrm{df}=20 \mathrm{I} ; \mathrm{p}$ value $<0,0 \mathrm{I}$ & Model Tidak fit \\
RSMEA & 0,048 & Model Fit \\
CFI & 0,943 & Model Fit \\
TLI & 0,934 & Model Fit \\
\hline
\end{tabular}

Tabel 3 memperlihatkan bahwa dari empat indeks fit yang digunakan dalam penelitian ini menunjukkan tiga indeks fit (RMSEA, CFI dan TLI) menyatakan bahwa model fit terhadap data. Dengan demikian dinyatakan bahwa model 3-correlated factor dapat diterima meskipun indek fit Chi-square melaporkan tidak fit. Adapun pertimbangan tidak menggunakan indeks fit Chi-square dalam menyimpulkan model yang cocok dalam penelitian ini karena indeks fit Chi-square memiliki kelemahan, yaitu indeks fit yang sangat sensitive dipengaruhi oleh jumlah sampel terutama jika melakukan analisis data dengan menggunakan sampel besar di atas 200 (Hoe, 2018). 


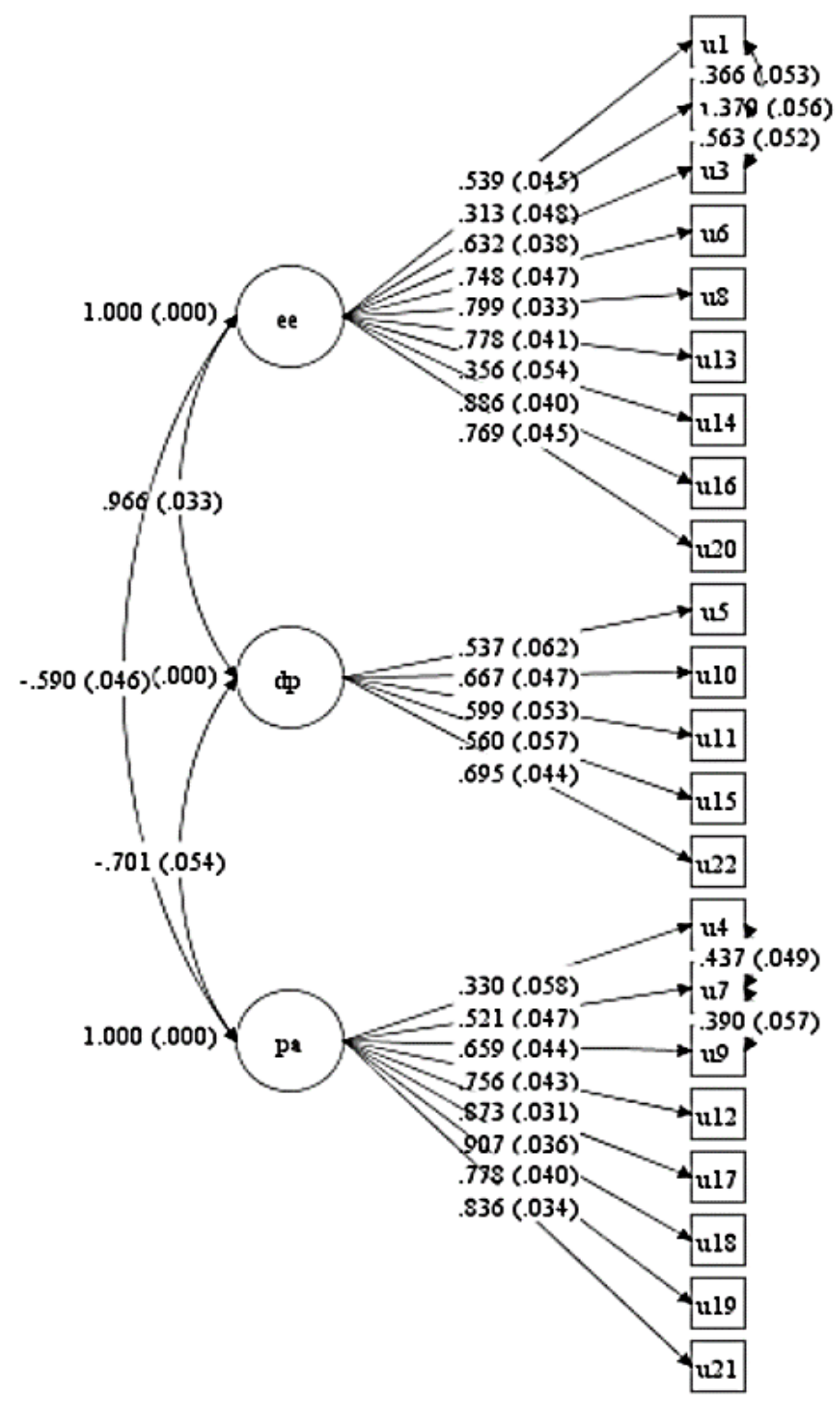

Gambar I. Path Diagram Model 3-Correlated Factor MBI-HSS

Keterangan: ee $=$ Emotional Exhaustion, $\mathrm{dp}=$ Depersonalisation, pa $=$ Personal Accomplishment, Chi-Square $=429,588 ; \mathrm{df}=$ 20I; $\mathrm{p}$ value $<0,0 \mathrm{I} ; \mathrm{RSMEA}=0,048 ; \mathrm{CFI}=0,943 ; \mathrm{TLI}=0,934$

Tabel 4. Korelasi antar faktor skala MBI

\begin{tabular}{lll}
\hline & Emotional Exhaustion & Depersonalisation \\
\hline Depersonalisasation & 0,966 & - \\
Personal Accomplishment & $-0,590$ & $-0,70 \mathrm{I}$ \\
\hline
\end{tabular}

Setelah didapatkan nilai indeks RSMEA 0,048 $(<0,05)$, indeks CFI 0,943 $>0,090)$ dan indeks TLI $0,934(>0,090)$ dapat dinyatakan bahwa model 3-correlated factor dapat diterima, artinya ketiga dimensi burnout berdiri sendiri-sendiri akan tetapi saling berkorelasi satu sama lain. Dari hasil uji pada Tabel 4 menunjukkan antara faktor Emotional Exhaustion dan faktor Depersonalisation berkorelasi cukup kuat dan positif sedangkan faktor Personal Accomplishment berkorelasi lebih lemah dan negatif terhadap kedua faktor lainnya.

Setelah ditemukan model fit, selanjutnya melihat estimasi setiap item apakah item tersebut valid atau tidak. Pengujian ini dilakukan dengan melihat nilai t bagi setiap koefisien, seperti ditunjukkan pada Tabel 5. 
Tabel 5. Muatan Faktor Item MBI setelah Model Fit

\begin{tabular}{|c|c|c|c|c|}
\hline \multicolumn{5}{|c|}{ Emotional exhaustion } \\
\hline No. item & Koefisien & Standar error & $t$-value & Keterangan \\
\hline I & 0,539 & 0,045 & $\mathrm{I} 2,032$ & Item valid \\
\hline 2 & 0,313 & 0,048 & 6,518 & Item valid \\
\hline 3 & 0,632 & 0,038 & I6,6I I & Item valid \\
\hline 6 & 0,748 & 0,047 & $\mathrm{I} 5,99 \mathrm{I}$ & Item valid \\
\hline 8 & 0,799 & 0,033 & $24,30 \mathrm{I}$ & Item valid \\
\hline $\mathrm{I} 3$ & 0,778 & $0,04 \mathrm{I}$ & 19,195 & Item valid \\
\hline $\mathrm{I} 4$ & 0,356 & 0,054 & 6,543 & Item valid \\
\hline 16 & 0,886 & 0,040 & 22,306 & Item valid \\
\hline 20 & 0,769 & 0,045 & I7,I94 & Item valid \\
\hline
\end{tabular}

\begin{tabular}{|c|c|c|c|c|}
\hline \multicolumn{5}{|c|}{ Depersonalisation } \\
\hline 5 & 0,537 & 0,062 & 8,707 & Item valid \\
\hline 10 & 0,667 & 0,047 & I4,303 & Item valid \\
\hline II & 0,599 & 0,053 & I I,34I & Item valid \\
\hline I5 & 0,56 & 0,057 & 9,886 & Item valid \\
\hline 22 & 0,695 & 0,044 & I5,796 & Item valid \\
\hline
\end{tabular}

\begin{tabular}{|c|c|c|c|c|}
\hline \multicolumn{5}{|c|}{ Reduce Personal Accomplishment } \\
\hline 4 & 0,33 & 0,058 & 5,669 & Item valid \\
\hline 7 & 0,521 & 0,047 & II,I & Item valid \\
\hline 9 & 0,659 & 0,044 & I5,083 & Item valid \\
\hline 12 & 0,756 & 0,043 & 17,478 & Item valid \\
\hline 17 & 0,873 & $0,03 \mathrm{I}$ & 27,887 & Item valid \\
\hline 18 & 0,907 & 0,036 & 24,893 & Item valid \\
\hline 19 & 0,778 & 0,040 & 19,496 & Item valid \\
\hline 21 & 0,836 & 0,034 & 24,702 & Item valid \\
\hline
\end{tabular}

Pada Tabel 5 memperlihatkan bahwa seluruh item memiliki nilai koefisien positif dan $t$-value $>$ I,96 sehingga dapat dikatakan bahwa item-item pada skala MBI tersebut valid mengukur ketiga dimensi Emotional exhaustion, Depersonalisation dan Reduce Personal Accomplishment. Dari nilai koefisien tidak terdapat item yang muatan faktornya negatif. Artinya semakin tinggi nilai pada item maka semakin tinggi pula nilai pada faktor yang diukur. Keseluruhan item pada skala MBI memberikan muatan faktor yang cukup tinggi yaitu berkisar antara 0,3I3 hingga 0,907.

Langkah selanjutnya adalah melihat apakah model pengukuran dalam penelitian ini terdapat kesalahan pengukuran item yang saling berkorelasi. Artinya bahwa item-item tersebut bersifat multidimensional atau tidak hanya mengukur satu faktor saja. Pada Tabel 4 sebelumnya, peneliti memaparkan korelasi antarkesalahan pengukuran dari item-item pada skala MBI.

Tabel 6. Korelasi Antarkesalahan Pengukuran Item MBI

\begin{tabular}{lllll}
\hline No item & Koefisien & Standar error & t-value & keterangan \\
\hline 3 with 2 & 0,563 & 0,052 & I0,8 & Signifikan \\
3 with I & 0,370 & 0,056 & 6,648 & Signifikan \\
7 with 4 & 0,437 & 0,049 & 8,969 & Signifikan \\
2 with I & 0,366 & 0,053 & 6,913 & Signifikan \\
9 with 7 & 0,390 & 0,057 & 6,825 & Signifikan \\
\hline
\end{tabular}


Tabel 6 menjelaskan bahwa model 3-correlated factor menjadi fit setelah kesalahan-kesalahan antaritemitem dibiarkan berkorelasi. Dalam tabel tersebut memberikan informasi adanya item yang berkorelasi dengan item lain, yaitu item nomor 4 dan 9 berkorelasi satu kali dan item nomor I, 2, 3, dan 7 berkorelasi dua kali. Dalam hal ini digunakan kriteria lebih dari 3 (tiga) kali berkorelasi, yang artinya apabila terdapat item yang berkorelasi dengan item lain lebih dari 3 (tiga) kali akan dieliminasi, sehingga item tersebut tidak dapat diikutsertakan dalam analisis perhitungan skor faktor. Namun dalam skala MBI tidak terdapat item yang memiliki kriteria tersebut, sehingga dalam penelitian ini tidak ada item yang akan dieliminasi.

Dari hasil analisis data menggunakan software Mplus version 7.II menghasilkan model (Tabel 3) yang menghasilkan hubungan yang bermakna dan signifikan sesuai data: $X^{2}(20 \mathrm{I})=429,588$; $\mathrm{p}<0,0 \mathrm{I}$; RSMEA $=0,048$; CFI 0,943; TLI; 0,934; $\mathrm{n}=504$.

I. Indeks Nilai Chi-square adalah 429,588; $\mathrm{df}=20 \mathrm{I} ; \mathrm{p}<0$,0I. Indeks Chi square tersebut menunjukkan bahwa ada perbedaan antara data dan mode, sehingga model dikatakan tidak fit terhadap data. Signifikansi dari Chi-square yang diharapkan adalah yang nilainya tidak signifikan yang artinya kesalahan pada model tidak signifikan (Wang \& Wang, 20I2). Namun, karena Chi-square sensitif terhadap ukuran sampel sehingga tidak boleh digunakan sebagai satu-satunya panduan untuk kesesuaian model (Hu \& Bentler, I999).

2. Indeks RMSEA adalah 0,048. Nilai indeks RMSEA < 0,05 mengindikasikan bahwa data fit terhadap model (Wang \& Wang, 2012).

3. Index CFI adalah 0,943. Besaran indeks ini adalah dalam rentang 0 sampai I dan nilai yang mendekati I mengindikasikan model memiliki tingkat kesesuaian yang baik. Nilai indeks CFI $>0,90$ mengindikasikan data fit dengan model. (Hu \& Bentler, I999).

4. Indeks TLI adalah 0,934. Nilai indeks yang direkomendasikan adalah nilai TLI $>0,90$ mengindikasikan data fit dengan model (Hu \& Bentler, 1999).

Dari hasil uji dengan menggunakan pendekatan Confirmatory Factor Ananysis (CFA) dilaporkan bahwa seluruh item dalam skala MBI adalah valid tidak ada satupun dari 22 item yang harus dieliminasi. Hal ini tidak sejalan dengan hasil temuan peneliti sebelumnya (Loera et al., 20I4; Richardsen \& Martinussen, 2004; Vanheule et al., 2007) yang menyarankan agar item no 12 dan I6 dieliminasi karena memberikan kontribusi yang rendah disebabkan memiliki cross loading yang tinggi.

Hasil penelitian menunjukkan bahwa semua item dalam skala MBI yang telah diadaptasi dan digunakan kepada anggota kepolisian adalah fit (sesuai) dengan model 3-correlated factor yang menunjukkan antara faktor Emotional Exhaustion dan faktor Depersonalisation berkorelasi cukup kuat dan positif sedangkan faktor Personal Accomplishment berkorelasi lebih lemah dan negative terhadap kedua faktor lainnya. Hasil ini sejalan dengan beberapa temuan beberapa peneliti sebelumnya (Bennett, I995; Loera et al., 20I4; Poghosyan et al., 2009; Richardsen \& Martinussen, 2004).

\section{Penutup}

Kesimpulan dalam penelitian ini, ditemukan bahwa skala MBI yang telah diadaptasi dan digunakan dalam sampel anggota kepolisian dapat digunakan pada penelitian berikutnya karena seluruh item bernilai valid, signifikan dan tidak ada satu pun item yang memiliki muatan faktor negatif. Hanya saja terdapat beberapa item yang memiliki korelasi dengan item lain sehingga dilakukan modifikasi dengan cara melepaskan korelasinya dengan melihat error yang paling tinggi sehingga didapatkan model unidimensional. Pada dimensi Emotional Exhaustion, item no 3 "Saya merasa lelah saat bangun pagi karena harus memulai tugas hari ini" berkorelasi dengan item no 2 "Saya merasa kelelahan setelah bekerja seharian" dan item no I "Saya merasa beban pekerjaan saya menguras emosi saya" dimana item no 2 juga berkorelasi dengan item no I. Pada dimensi 
Personal Accomplishment item no 7 "Saya dapat menangani permasalahan orang lain dengan sangat efektif" berkorelasi dengan 2 item lainnya pada no 4 "Saya dapat dengan mudah memahami perasaan orang lain" dan item no 9 "Saya merasa dapat memberikan pengaruh positif terhadap orang lain melalui pekerjaan saya".

Untuk penelitian lebih lanjut peneliti memiliki beberapa saran, yaitu: (I) Pada pemilihan responden agar lebih memperhitungkan keterwakilan dalam bidang penugasan, karena pada setiap bidang penugasan baik bidang operasional maupun pembinaan memiliki tingkat risiko dan stress yang berbeda. Misalnya pada bidang penugasan operasional, dimana polisi bertugas langsung berhadapan dengan penjahat dan pelaku tindak pidana. Bidang pengendalian massa, dimana polisi bertugas langsung berhadapan dengan kelompok massa yang sering berperilaku anarkis. Bidang pasukan penindak pada gangguan keamanan tingkat tinggi yang sering berhadapan langsung dengan teroris baik di hutan maupun kota, serta pada bidang penugasan lainnya. (2) Tempat penugasan pada tingkat Polsek, Polres maupun Polda agar menjadi salah satu hal yang diperhatikan, mengingat luas wilayah yang menjadi tanggung jawab dalam pekerjaannya memberikan pengaruh terhadap beban kerja anggota polisi. (3) Memperluas variasi sampel agar tidak terbatas hanya pada anggota kepolisian yang berdinas di Polda Metro Jaya, sehingga keterwakilan sampel polisi di Indonesia terpenuhi serta memperhatikan keberagaman sampel yang digunakan misalnya, dengan lebih memperhitungkan jumlah keterwakilan laki-laki dan wanita, serta golongan kepangkatan.

\section{Daftar Pustaka}

Beaton, D. E., Bombardier, C., Guillemin, F., \& Ferraz, M. B. (2000). Guidelines for the Process of CrossCultural Adaptation of Self-Report Measures. 3186-3I9I.

Bennett, L. (1995). Health Workers and Aids. Boca Raton, FL: CRC Press.

Chirico, F. (2016). Job stress models for predicting burnout syndrome: A review. Annali Dell'Istituto Superiore Di Sanità, 3.

Hatta, H.R. \& Noor, H. 20I4. Hubungan Antara Hardiness Dengan Burnout Pada Anggota Polisi Pengendali Massa (Dalmas) Polrestabes Bandung. Jurnal Gel. 2. ISSN: 2460-6448.

Hoe, S. L. (2018). Issues and Procedures in Adopting Stuctural Equation Modeling Technique. Journal of Apllied Quantitative Methods, 3, 76-83.

Horn, J.E. Van, \& Schaufeli, WB. (1998). The Dutch Educators Survey (MBI-NLES) Psychometric evaluations. Utrecht University: Department of Social and Organizational Psychology.

Hu, L., \& Bentler, P. M. (I999). Cutoff criteria for fit indexes in covariance structure analysis: Conventional criteria versus new alternatives. Structural Equation Modeling: A Multidisciplinary Journal, 6(I), I-55. https://doi.org/I0.1080/I0705519909540118.

Loera, B., Converso, D., \& Viotti, S. (20I4). Evaluating the Psychometric Properties of the Maslach Burnout Inventory-Human Services Survey (MBI-HSS) among Italian Nurses: How Many Factors Must a Researcher Consider? PLoS ONE, Y(I2), eI I4987.

Manapsal, J. P. (2017). A Comparative Study on Classical Test Theory and Rasch Model in Comprehensive Mental Ability Test (CMAT): A Pilot Test. International Journal of Sciences, 33(2), 266-283.

Maslach, C., \& Jackson, S. E. (198I). The measurement of experienced burnout. Journal of Organizational Behavior, 2(2), 99-II3.

Maslach, C., Schaufeli, W. B., \& Leiter, M. P. (200I). Job Burnout. Annual Review of Psychology, 52(I), 397-422. 
Muarif, A. (2015). Pengaruh pelatihan emotional intelligence terhadap burnout pada petugas kepolisian. Tesis. Universitas Gajah Mada.

Muthen, L. K., \& Muthen, B. O. (1998). Mplus User’s Guide(7th ed.).

Nikam, P.K. \& Shaikh, M. (20I4). Occupational Stress, Burnout and Coping in Police Personel: Finding from a Systematic Review. American InternationalJournal of Research in Humanities, Arts and Social Scienes. ISSN (Print): 2328-3734.

Poghosyan, L., Aiken, L. H., \& Sloane, D. M. (2009). Factor structure of the Maslach burnout inventory: An analysis of data from large scale cross-sectional surveys of nurses from eight countries. International Journal of Nursing Studies, 46(7), 894-902.

Purda, Valeria, N., Liliana, \& Amelia. (2012). Burnout - an Effect of Professional Stress in the Police Environment. International Conference on Economics, Trade and Development IPEDR, vol.36.

Putra, M. J. B \& Prihatsanti, U. (2017). Hubungan Antara Gaya Kepemimpinan Melayani dengan Kecenderungan Burnout pada Anggota Detasemen Gegana Satuan Brigade Mobil (Brimob) Kepolisian Daerah Jawa Tengah (Polda Jateng). Jurnal Empati. Volume 6 (I), 29I-295.

Queiros, C., Kaiseller, M \& Da Silva, A.N. (2013). Burnout as Predictor of Aggressivity Among Police Officer. European Journal of Policing Studis, I (2), IIO-I35. ISSN 2034-760.

Retnawati, H. (2017). Validitas Reliabilitas \& Karakteristik butit. Yogyakarta: Parama Publishing.

Richardsen, A. M., \& Martinussen, M. (2004). The Maslach Burnout Inventory: Factorial validity and consistency across occupational groups in Norway. Journal of Occupational and Organizational Psychology, 773), 377-384. https://doi.org/I0.1348/096317904I75269I.

Umar, J. (20I I). Bahan ajar psikometri. Tidak diterbitkan.

Vanheule, S., Rosseel, Y., \& Vlerick, P. (2007). The factorial validity and measurement invariance of the Maslach Burnout Inventory for human services. Stress and Health, 23(2), 87-9I.

Wang, J., \& Wang, X. (2012). Structural Equation Modeling: Applications using Mplus. Chichester: John Wiley \& Sons. http://dx.doi.org/I0.1002/978I I 18356258. 